EXTENDED REPORT

\title{
Chondrocyte number and proteoglycan synthesis in the aging and osteoarthritic human articular cartilage
}

\author{
K Bobacz, L Erlacher, J Smolen, A Soleiman, W B Graninger
}

Ann Rheum Dis 2004;63:1618-1622. doi: 10.1136/ard.2002.002162

See end of article for authors' affiliations

Correspondence to

Correspondence to:
Dr K Bobacz, Department of Rheumatology, Internal Medicine III, Allgemeines Krankenhaus, Waehringer Guertel 18-20, A-1090

Vienna, Austria; klaus.

bobacz@univie.ac.at

Accepted

18 February 2004

\begin{abstract}
Objective: To correlate the number of chondrocytes in healthy and osteoarthritic human articular cartilage with age, and to evaluate the influence of donor age on total proteoglycan synthesis.

Methods: Chondrocytes were isolated from human articular cartilage derived from hip joints with and without osteoarthritic lesions. The cell number was normalised to cartilage sample wet weight. In addition, the influence of age on chondrocyte numbers was assessed histomorphometrically. Chondrocytes were grown as monolayer cultures for seven days in a chemically defined serum-free basal medium. Total proteoglycan synthesis was measured by $\left[{ }^{35} \mathrm{~S}\right]$ sulphate incorporation into newly synthesised macromolecules.

Results: Chondrocyte numbers in healthy cartilage decreased significantly with advancing age $(r=-0.69$, $\mathrm{p}<0.0001$ ). In contrast to healthy specimens, chondrocyte numbers were decreased in osteoarthritic cartilage irrespective of and unrelated to age, and differed markedly, by an average of $38 \%$, from the cell numbers found in healthy individuals $(p<0.0001)$. Regarding synthesis of matrix macromolecules, no dependence on patients' age, either in healthy or in osteoarthritic specimens, could be observed.

Conclusions: Under the experimental conditions employed, chondrocytes from healthy and osteoarthritic joints synthesised comparable amounts of cartilage macromolecules, independent of age or underlying osteoarthritic disease. Thus the decrease in chondrocyte number in aging and osteoarthritic joints could be a crucial factor in limiting tissue replenishment.
\end{abstract}

A ging is associated with progressive structural, functional, and metabolic alterations in a variety of tissues and systems. Many of these age related alterations have been implicated in subsequent impairment of physiological and physical function. ${ }^{1}$ Functional changes in the musculoskeletal system are among the most prevalent health problems of middle and old age. ${ }^{2}$ Osteoarthritis, the most common form of joint disease, is highly correlated with increasing age. ${ }^{3-5}$ Despite the strong relation between age and increased prevalence of degenerative cartilage changes, the underlying mechanisms whereby age is involved in the development or progression of osteoarthritis are so far unknown. ${ }^{67}$

Important age dependent changes in articular cartilagewhich increase in prevalence, extent, and severity with advancing age $\mathrm{e}^{8-10}$ — concern matrix macromolecules (MMM) such as proteoglycans and collagens. Qualitative and quantitative variances in these components are observed, suggesting an alteration in the physiological cartilage composition and mechanical properties. ${ }^{2}{ }^{11-17}$ Moreover, and possibly more important, an age related reduction in total proteoglycan synthesis after skeletal maturation has been reported. ${ }^{18-20}$

The role and influence of chondrocytes in this condition remain unclear. Several studies have suggested that the cell density of the whole thickness of the uncalcified articular cartilage declines sharply during the growth and maturation period of skeletal development, but remains relatively constant in adult life. ${ }^{21-24}$ On the other hand there is evidence that chondrocyte numbers decrease progressively in healthy articular cartilage as a function of age. ${ }^{25-28}$

Given the reduction in total proteoglycan synthesis with advancing age, we hypothesised that a decline in cell number was an important factor in limiting tissue maintenance. Thus we evaluated the cell numbers in healthy and osteoarthritic human articular cartilage in relation to increasing age, and investigated total MMM synthesis in healthy and osteoar- thritic cartilage to determine a possible influence of age on proteoglycan production.

\section{METHODS}

\section{Source of articular cartilage}

Human articular cartilage from 41 patients (aged 37 to 87 years, mean age 62.9 years) without macroscopic osteoarthritic lesions were obtained from surgical specimens at the time of endoprosthetic replacement for acute transcervical femoral fractures and from organ donors.

The removal of cartilage from organ donors was approved by the ethics committee of the University of Vienna.

Human osteoarthritic cartilage samples were obtained from 30 individuals who underwent surgery for total hip endoprosthesis. The age of the patients ranged from 35 to 84 years with a mean age of 61.8 years.

\section{Cell count and cell culture}

Cartilage slices were aseptically dissected from the load bearing joint surfaces and finely minced. In osteoarthritis specimens, dissection of neocartilage at the joint margins was avoided. The wet weight of the samples obtained was then measured. Chondrocytes were released by overnight digestion in $0.2 \%$ collagenase $\mathrm{B}$ (Boehringer Mannheim, Mannheim, Germany) in a recently described, chemically defined, serum-free basal medium. ${ }^{29}$ Following digestion, an aliquot of the cell suspension was evaluated for chondrocyte number after Trypan blue staining in a Buerker-Tuerk chamber. The values are given in chondrocytes $\times 10^{6} / \mathrm{g}$ wet weight. The fraction of dead chondrocytes was $5-10 \%$, independent of advanced age or underlying osteoarthritic disease. In both osteoarthritic and unaffected cartilage samples, cell clusters formed about $2 \%$ of all chondrocytes and could easily be counted. To ensure completeness of tissue digestion, the suspension after collagenase incubation was subsequently filtered using a cell strainer (Falcon, Becton 


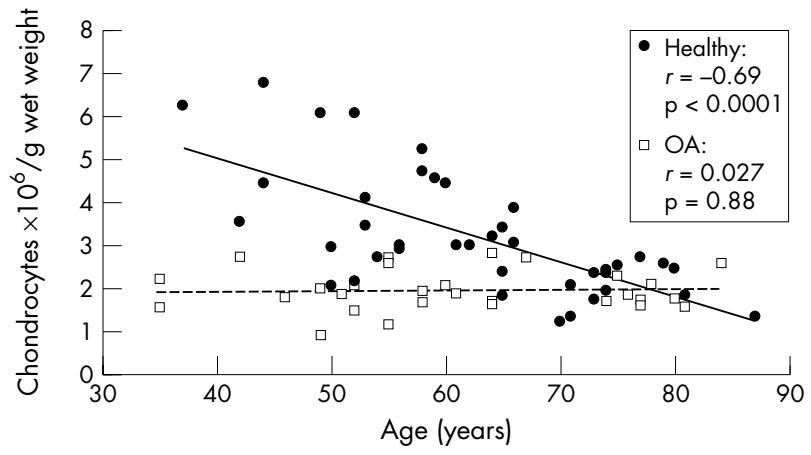

Figure 1 Changes in the total chondrocyte numbers of healthy and osteoarthritic articular cartilage with increasing age. Chondrocytes were enzymatically released from their extracellular matrix in $0.2 \%$

collagenase B. Directly after digestion cell numbers were assessed using light microscopy. The values are given as chondrocytes $\times 10^{6} / \mathrm{g}$ wet weight. There was a decrease in chondrocyte numbers in healthy articular cartilage (black circles, black regression line) as a function of age $(n=41 ; r=-0.69, p<0.0001)$. Cellularity in osteoarthritic cartilage (white squares, dashed regression line) showed a significant reduction in cell number compared with healthy cartilage $(p<0.0001)$, but no dependence on patients' age $(n=30 ; r=0.027, p=0.88)$.

Dickinson Labware, Lincoln Park, New Jersey, USA), and the weight of the solid residues determined on a microgram scale. The percentage of solid residues after collagenase digestion was uniformly between $1.3 \%$ and $5.9 \%$ of the cartilage weight, with no difference between healthy and osteoarthritic samples $(p=0.46)$.

In an additional series of experiments, the influence of age on chondrocyte numbers was assessed histomorphometrically. We investigated histological samples from hip joints from 14 unaffected donors (aged 24 to 68 years, mean 43.5 years) and from 17 patients with osteoarthritis (aged 38 to 91 years, mean 70.4 years). Specimens of cartilage and subchondral bone were fixed in $7.5 \%$ formalin for 48 hours, decalcified with EDTA solution, and then paraffin embedded and stained with haematoxylin/eosin following standard protocols. Using the KS 300 version 3.0 software (Carl Zeiss Vision GmbH 1997) three randomly chosen full thickness cartilage areas were marked in each histological sample and the surface areas were calculated. The chondrocyte numbers were counted in the respective areas and the results are given as cell number $/ \mathrm{mm}^{2}$.

For cell cultures, the chondrocyte filtrate was centrifuged at $500 \times \mathrm{g}$ for 10 minutes. Pellets were resuspended in $1: 1$ mixture of Dulbecco's modified Eagle's medium (DMEM, $25 \mathrm{mM}$ Hepes + $4500 \mathrm{mg} / \mathrm{l}$ glucose + pyridoxine, without sodium pyruvate; Life Technologies, Gaithersburg, Maryland, USA) and Ham's F12 (Ham's F-12 +L-glutamine; Life Technologies) containing $10 \%$ fetal bovine serum (PAA Laboratories, Linz, Austria) and antibiotics/antimycotics ( $100 \mathrm{U} / \mathrm{ml}$ penicillin $\mathrm{G}, 100 \mathrm{mg} / \mathrm{ml}$ streptomycin, and 0.25 $\mu \mathrm{g} / \mathrm{ml}$ amphotericin B; Life Technologies). The isolated cells were grown as monolayer cultures in 24-well plates (Costar, Cambridge, Massachusetts, USA) in quadruplicate at a density of $1 \times 10^{5}$ cells $/ \mathrm{cm}^{2}$. At $90 \%$ confluence of the chondrocyte cultures (approximately $2 \times 10^{5}$ cells/well), serumcontaining medium was changed to basal medium and the cells were subsequently cultured for seven days. The medium was replaced every other day. Cultures were maintained at $37^{\circ} \mathrm{C}$ in humidified air and $5 \% \mathrm{CO}_{2}$.

\section{Biosynthesis of macromolecules}

Proteoglycan synthesis rate for 17 healthy samples (from subjects aged 37 to 80 years, mean age 58.6 years) and 12 osteoarthritis samples (aged 35 to 84 years, mean age

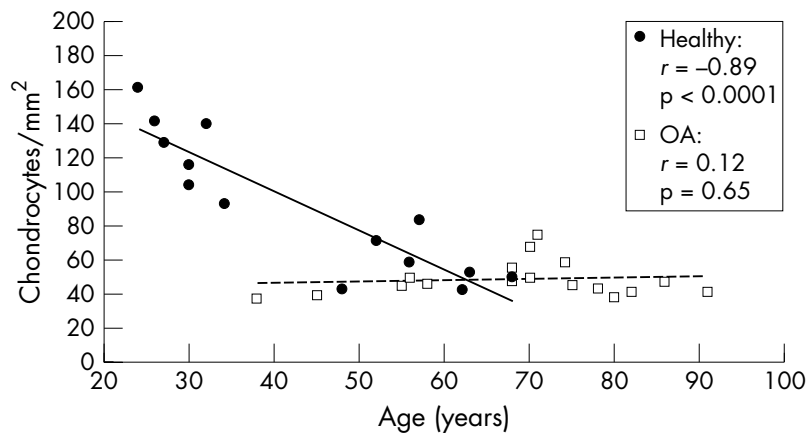

Figure 2 Chondrocyte numbers in histological sections from healthy and osteoarthritic cartilage. The values are given as chondrocytes $/ \mathrm{mm}^{2}$ cartilage. Chondrocyte numbers in healthy articular cartilage (black circles, black regression line) decrease as a function of age $(n=14$; $r=-0.89, p<0.0001$ ). In osteoarthritic cartilage (white squares, dashed regression line) no reduction in cell number could be seen ( $n=17$; $r=0.12, p<0.65$ ). Analysis of the healthy $v$ the osteoarthritic group showed a significant difference in cell numbers: healthy group, 91.6 (10.9) cells $/ \mathrm{mm}^{2}, v$ osteoarthritis group, 48.6 (2.5) cells $/ \mathrm{mm}^{2}$ (mean (SEM)), $p<0.007$.

58.6 years) was determined by $\left[{ }^{35} \mathrm{~S}\right]$ sulphate incorporation into sulphated glycosaminoglycans, as previously described..$^{30}$ Briefly, labelling of the cells with radioactivity was done by incubation with $20 \mu \mathrm{Ci} / \mathrm{ml}$ of $\left[{ }^{35} \mathrm{~S}\right]$ sulphate (carrier-free, Amersham, Buckinghamshire, UK) for six hours at $37^{\circ} \mathrm{C}$ in basal medium. Chondrocytes were extracted in guanidine$\mathrm{HCl}$ buffer (4 M guanidine- $\mathrm{HCl}, 50 \mathrm{mM}$ sodium acetate buffered at pH 7.2, in the presence of protease inhibitors). Unincorporated isotope was removed by using Sephadex G25 gel chromatography (PD-10 columns; Pharmacia Biotech, Piscataway, New Jersey, USA). Values were obtained by liquid scintillation counting (model 1410 liquid scintillation counter, Wallac Oy, Turku, Finland) of aliquots from void volume fractions and normalised to protein content. Total cellular protein was determined by the Bradford method according to the manufacturer's instructions (Bio-Rad Protein Assay; Bio Rad Laboratories GmbH, Munich, Germany).

\section{Statistical analysis}

Statistical analysis was done using Student's $t$ test. A normality test was carried out to determine whether the distribution of the samples was Gaussian. To examine relations between age and MMM synthesis rate, as well as between age and chondrocyte numbers, we used Pearson correlation calculations. Statistical significance was defined as a probability $(\mathrm{p})$ value of $<0.05$.

\section{RESULTS}

Effect of age on chondrocyte numbers of healthy and osteoarthritis human articular cartilage

The evaluation of chondrocyte numbers after tissue digestion revealed an age dependent decrease of cells in the cartilage samples derived from joints without macroscopically visible defects $(n=41)$. In the patient age group $<55$ years $(n=12)$, a mean $\left(\right.$ SEM) of $4.2(0.5) \times 10^{6}$ cells/g wet weight of cartilage was found, whereas cartilage from patients $>55$ years old $(\mathrm{n}=29)$ contained a mean of $2.7(0.2) \times 10^{6}$ chondrocytes $/ \mathrm{g}$ wet weight-a significant $(\mathrm{p}<0.002)$ decrease of $35 \%$ (fig 1 ; $r=-0.69, \mathrm{p}<0.0001)$. To further evaluate whether this reduction in cartilage cellularity reflects a possible mechanism for the onset or progression of osteoarthritis, we compared the data from the healthy samples with the chondrocyte numbers in 30 tissue samples obtained from osteoarthritic joints. In contrast to the healthy specimens, the 

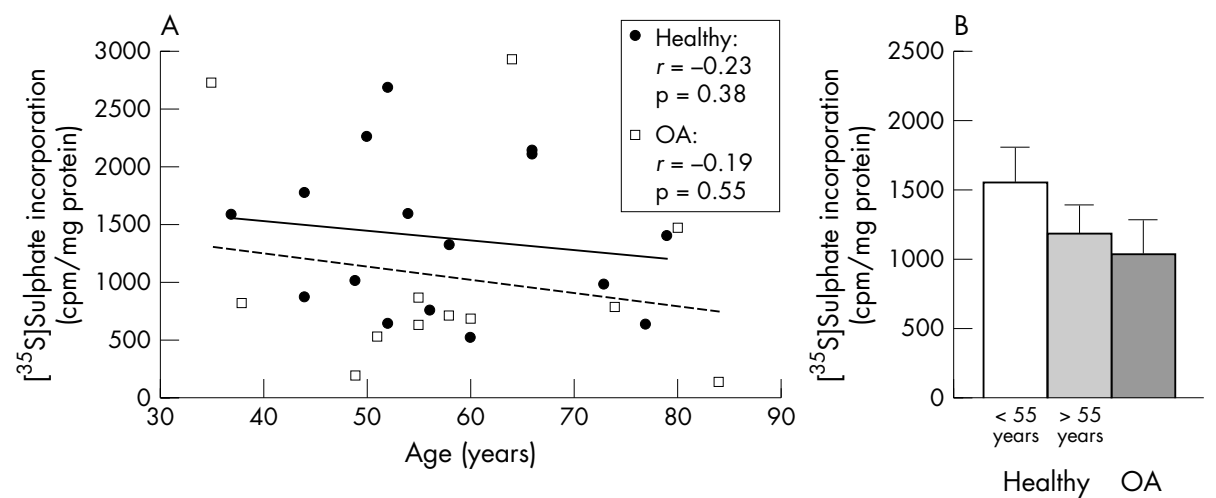

Figure 3 (A) Healthy (black circles, black regression line) and osteoarthritic (white squares, dashed regression line) human articular chondrocytes do not lose their biosynthetic capacity with age. Cells were cultured in serum-free basal medium without the addition of growth factors for seven days. The rate of proteoglycan synthesis was measured by $\left.{ }^{35} \mathrm{~S}\right]$ sulphate incorporation into newly synthesised matrix proteoglycans present in the cell layer. Values were normalised to protein content and are given as counts per $\mathrm{min} / \mathrm{mg}$ protein $(\mathrm{cpm} / \mathrm{mg}$ protein). No age dependent decrease in total proteoglycan synthesis could be shown for healthy chondrocytes $(r=-0.23, p=0.38)$ or osteoarthritic chondrocytes $(r=-0.19, p=0.55)$. (B) Proteoglycan synthesis of postnatal human articular chondrocytes. Chondrocytes derived from healthy patients $<55$ years (white bars, $n=8),>55$ years (light grey bars, $n=8$ ), and osteoarthritis patients (dark grey bars, $n=13$ ) were incubated in serum-free basal medium for seven days. On the final day of the incubation period, cell cultures were labelled with $\left.{ }^{35} \mathrm{~S}\right]$ sulphate for six hours. The incorporated radiolabel in newly synthesised matrix macromolecules present in the cell layer was then measured, normalised to protein content, and given as $\mathrm{cpm} / \mathrm{mg}$ protein. Values are mean (SEM). No difference between these groups could be determined (NS).

chondrocyte number in osteoarthritic cartilage had a mean (SEM) value of $1.9(0.1) \times 10^{6}$ cells/g wet weight, which differed markedly—by an average of $38 \%$-from the number found in healthy cartilaginous tissue $(\mathrm{p}<0.0001)$. It is noteworthy that the decrease in chondrocyte numbers was already evident in younger patients with osteoarthritis and did not change further as a function of age (fig $1 ; r=0.027$, $\mathrm{p}=0.88$ ).

To support the above data, we evaluated the chondrocyte numbers $/ \mathrm{mm}^{2}$ cartilage in histological sections from 14 healthy and 17 osteoarthritic patients. In accordance with the results from the cartilage digests, we found an age dependent decrease in cell numbers in healthy specimens $(r=-0.89, \mathrm{p}<0.0001)$ (fig 2$)$. In osteoarthritic patients no such decrease could be seen $(r=0.12, \mathrm{p}=0.65)$. When we compared the healthy group with the osteoarthritic group we found a significant difference in cell numbers: healthy group, 91.6 (10.9) cells $/ \mathrm{mm}^{2} v$ osteoarthritis group, 48.6 (2.5) cells/ $\mathrm{mm}^{2}, \mathrm{p}<0.007$.

\section{Effect of increasing age on biosynthetic activity in articular chondrocytes}

To investigate whether the levels of biosynthetic activity in healthy and osteoarthritic human articular chondrocytes-as determined by synthesis of MMM-decreases with advancing age, we investigated cartilage specimens from osteoarthritic and non-osteoarthritic patients at different ages. The chondrocytes were cultured in serum-free basal medium for seven days. In cells from healthy individuals, $\left[{ }^{35} \mathrm{~S}\right]$ sulphate incorporation rate ranged from 509 to $2689 \mathrm{cpm} / \mathrm{mg}$ protein, with an average of 1353 (161) cpm/mg protein (mean (SEM)). In osteoarthritis cultures, isotope uptake ranged from 118 to $2932 \mathrm{cpm} / \mathrm{mg}$ protein, with a mean of 1090 (249) $\mathrm{cpm} / \mathrm{mg}$ protein. Although there was a mild trend towards decreasing MMM synthesis with increasing age, these differences were not significant, either among healthy samples $(r=-0.23, \mathrm{p}=0.38)$ or among osteoarthritis samples $(r=-0.19, \mathrm{p}=0.55)$ (fig 3A). Importantly, when we divided the healthy patient group into a "young" group $(<55$ years) and an "old" group ( $>55$ years) and compared these groups with the osteoarthritis specimens (fig 3B), no significant difference could be observed $(<55$ years $v$ osteoarthritis, $\mathrm{p}=0.24 ;>55$ years $v$ osteoarthritis $\mathrm{p}=0.8$ ).

\section{DISCUSSION}

The ability of cells to maintain metabolic homeostasis is believed to decline with advancing age. ${ }^{6}$ Age represents a major risk factor for the occurrence of osteoarthritis. ${ }^{3}$ The question arises as to whether articular chondrocytes retain their capacity to uphold tissue homeostasis by synthesising matrix proteoglycans with advancing age. In the case of reduced biosynthetic activity, the maintenance of cartilage extracellular matrix would be impaired and subsequently lead to disruption of tissue integrity, as seen in osteoarthritis. Two possible underlying mechanisms for impaired proteoglycan synthesis in the aging articular cartilage could be a decrease in total cell number or a decline in proteoglycan synthesis rate.

Levels of biosynthetic activity may be decreased as a function of age or osteoarthritis, causing a breakdown of cartilage integrity. Under the experimental conditions employed in this study no such decrease-either with aging or with underlying osteoarthritis-was observed. On the other hand, there was a mild trend towards a decrease in macromolecular synthesis, and lack of statistical significance does not exclude the possibility that some patients with osteoarthritis may have a more severe impairment of proteoglycan biosynthesis. A possible limitation of the current study is that cell metabolic activity was assessed in monolayer cultures after initial expansion in serum-containing medium, thereby potentially overriding possible differences in metabolic activity between cells derived from osteoarthritic cartilage and controls. On the other hand, previous investigations did not show differences between explant cultures derived from osteoarthritic and healthy articular cartilage studied under serum-free conditions. ${ }^{31}$ Moreover, to minimise such potential effects, we exchanged the serum-containing to serum-free medium for seven days before assessing metabolic activity. Finally, in previous investigations we also did not observe dedifferentiation of cells under the experimental conditions employed..$^{32} 33$ Nevertheless our data are in agreement with the reports by Lafeber and Brocklehurst, who previously described no difference in proteoglycan biosynthetic rate between healthy and osteoarthritic cartilage. ${ }^{3134}$ A constant rate of proteoglycan biosynthesis in healthy articular chondrocytes between 30 and 95 years was also shown by Bayliss and colleagues. ${ }^{35}$ 
However, contrary findings were reported by Schafer et al, ${ }^{18}$ DeGroot et al, ${ }^{19}$ and Verbruggen et al, ${ }^{20}$ who all showed a significant reduction in proteoglycan synthesis as a result of aging. A possible explanation for these contradictory findings may be the use of different culture techniques. It must be assumed that all these results are valid, but studies employing in vivo rather than cell culture conditions may have to take mechanisms other than failure of chondrocyte metabolism into account.

As the cell counts in the monolayer cultures employed here were constant we assume that the age dependent reduction of biosynthetic activity is caused by an impaired cartilage cellularity, because it is well known that chondrocyte numbers decrease in healthy articular cartilage as a function of age. ${ }^{25-28}$ Furthermore it was reported that cell numbers in osteoarthritic cartilage declined in both fissured and intact joint surface areas compared with healthy specimens. ${ }^{28} 36$ Our present study confirms these data on healthy cartilage, showing a decrease in chondrocyte number with advancing age. In addition we found that cell numbers are markedly reduced in osteoarthritic patients independently of age, even in young patients. Thus the loss in MMM from articular cartilage-which represents an early event in osteoarthritis ${ }^{37}$ - may be caused primarily by a decrease in cartilage cellularity. Moreover, with respect to the changes in matrix composition in old age and osteoarthritis, ${ }^{211} 1217$ it is likely that a reduction in chondrocyte numbers plays a role in these condition, as the production of inappropriate non-cartilagespecific matrix constituents ${ }^{38} 39$ may be caused by an exhaustion or premature aging of the remaining cells.

The mechanisms leading to a loss of chondrocytes in aging and osteoarthritis are still unknown but it may result from a loss of responsiveness to anabolic growth factors ${ }^{40}$ or possibly from cell death. ${ }^{41}{ }^{42}$ Whether the state of reduced tissue cellularity reflects cause or outcome of the osteoarthritic disease process is yet to be investigated.

\section{Conclusions}

We found an age related decrease in chondrocyte numbers in healthy cartilage, whereas cell counts in osteoarthritic tissue were reduced at all ages, even in younger patients. Chondrocytes released from cartilage samples synthesised similar amounts of MMM, regardless of their provenancethat is, whether they were from younger or older healthy cartilage or from osteoarthritic cartilage. These findings suggest that the reduction in cartilage cellularity may be an important factor in impairing tissue maintenance during aging and in osteoarthritis.

\section{Authors' affiliations}

K Bobacz, L Erlacher, J Smolen, W B Graninger, Department of Rheumatology, Internal Medicine III, University of Vienna, Vienna, Austria

A Soleiman, Department of Pathology, University of Vienna

\section{REFERENCES}

1 Sherman S. Human Aging at the millennium. In: Rosen C, Glowacki J, Bilezikian J, eds. The aging skeleton. New York: Academic Press, 1999:11-18.

2 Buckwalter J, Woo S, Goldberg V, Hadley E, Booth F, Oegema T, et al. Softtissue aging and musculoskeletal function. J Bone Joint Surg Am 1993;75:1533-48.

3 Creamer P, Hochberg MC. Osteoarthritis. Lancet 1997;350:503-8.

4 Davis M, Ettinger W, Neuhaus J, Mallon K. Knee osteoarthritis and physical functioning: evidence from the NHANES I epidemiologic follow up study. J Rheumatol 1991;18:591-8.

5 Felson D. The epidemiology of knee osteoarthritis: results from the Framingham osteoarthritis study. Semin Arthritis Rheum 1990;20(suppl 1):42-50

6 Buckwalter J, Woo S, Goldberg V, Hadley E, Booth F, Oegema T, et al. Softtissue aging and musculoskeletal function. J Bone Joint Surg Am 1993;75:1533-48.
7 Hamerman D. Aging and osteoarthritis: basic mechanisms. J Am Geriatr Soc 1993;41:760-70

8 Peyron JG. Risk factors in osteoarthritis - how do they work? J Rheumatol 1987; 14(suppl 14):1-2.

9 Sokoloff L. Loading and motion in relation to ageing and degeneration of joints: implications for prevention and treatment of osteoarthritis. In: Helminen H, Kiviranta I, Tammi M, Saamanen A, Paukkonen K, Jurvelin J, eds. Joint loading: biology and health of articular structures. Bristol: John Wright, 1987:412-24.

10 Sokoloff L. Aging and degenerative diseases affecting cartilage. In: Hall B, eds. Cartilage. New York: Academic Press, 7983:109-41

11 Buckwalter J, Roughley P, Rosenberg L. Age-related changes in cartilage proteoglycans: quantitative electron microscopic studies. Microsc Res Tech 1994;28:398-408.

12 Buckwalter J, Rosenberg L. Electron microscopic studies of cartilage proteoglycans. Direct evidence for the variable length of the chondroitin sulfate-rich region of proteoglycan subunit core protein. J Biol Chem 1982;257:9830-9.

13 Maroudas A, Ziv I, Weisman N, Venn M. Studies of hydration and swelling pressure in normal and osteoarthritic cartilage. Biorheology 1985;22:159-69.

14 Venn M. Variation of chemical composition with age in human femoral head cartilage. Ann Rheum Dis 1978;37:168-74.

15 Kempson G. Age-related changes in the tensile properties of human articular cartilage: a comparative study between the femoral head of the hip joint and the talus of the ankle joint. Biochim Biophys Acta 1991;1075:223-30.

16 Weightman B. Tensile fatigue of human articular cartilage. J Biomech 1976;9:193-200

17 Hardingham T, Bayliss M. Proteoglycans of articular cartilage: changes in aging and in joint disease. Semin Arthritis Rheum 1990;20(suppl 1):12-33.

18 Schafer SJ, Luyten FP, Yanagishita M, Reddi AH. Proteoglycan metabolism is age related and modulated by isoforms of platelet-derived growth factor in bovine articular cartilage explant cultures. Arch Biochem Biophys 1993;302:431-8.

19 DeGroot J, Verziil N, Bank RA, Lafeber FP, Biilsma JW, TeKoppele JM. Agerelated decrease in proteoglycan synthesis of human articular chondrocytes: the role of nonenzymatic glycation. Arthritis Rheum 1999;42:1003-9.

20 Verbruggen G, Cornelissen M, Almgvist KF, Wang L, Elewaut D, Broddelez C, et al. Influence of aging on the synthesis and morphology of the aggrecans synthesized by differentiated human articular chondrocytes. Osteoarthritis Cartilage 2000;8:170-9.

21 Meachim G, Collins D. Cell count of normal and osteoarthritic articular cartilage in relation to the uptake of sulphate $\left({ }^{35} \mathrm{SO}_{4}\right)$ in vitro. Ann Rheum Dis 1962;21:45-9.

22 Miles J, Eichelberger L. Biochemical studies of human cartilage during the aging process. J Am Geriatr Soc 1964;12:1

23 Stockwell R. The cell density of human articular and costal cartilage. J Anat 1967;101:753.

24 Huch K. Knee and ankle: human joints with different susceptibility to osteoarthritis reveal different cartilage cellularity and matrix synthesis in vitro. Arch Orthop Trauma Surg 2001;121:301-6.

25 Vignon $E$, Arlot $M$, Patricot $L M$, Vignon $G$. The cell density of human femoral head cartilage. Clin Orthop 1976;121:303-8.

26 Quintero M, Mitrovic DR, Stankovic A, de Seze S, Miravet L, Ryckewaert A. Cellular aspects of the aging of articular cartilage. I. Condylar cartilage with a normal surface sampled from normal knees. Rev Rheum 1984:51:375-9.

27 Muehleman C, Chubinskaya S, Cole AA, Noskina Y, Arsenis C, Kuettner KE. Morphological and biochemical properties of metatarsophalangeal joint cartilage. J Am Podiatr Med Assoc 1997;87:447-59.

28 Mitrovic D, Quintero M, Stankovic A, Ryckewaert A. Cell density of adult human femoral condylar articular cartilage. Joints with normal and fibrillated surfaces. Lab Invest 1983;49:309-16.

29 Erlacher L, McCartney J, Piek E, Dijke PT, Yanagishita M, Oppermann H, et al. Cartilage-derived morphogenetic proteins and osteogenic protein-1 differentially regulate osteogenesis. J Bone Miner Res 1998;13:383-91.

30 Luyten FP, Yu YM, Yanagishita M, Vukicevic S, Hammonds RG, Reddi AH. Natural bovine osteogenin and recombinant human bone morphogenetic protein- $2 \mathrm{~B}$ are equipotent in the maintenance of proteoglycans in bovine articular cartilage explant cultures. J Biol Chem 1992;267:3691-5.

31 Lafeber FP, van der Kraan PM, Huber-Bruning $O$, van den Berg WB, Bijlsma JW. Osteoarthritic human cartilage is more sensitive to transforming growth factor beta than is normal cartilage. $\mathrm{Br} J$ Rheumatol 1993;32:281-6.

32 Bobacz K, Gruber R, Soleiman A, Graninger WB, Luyten FP, Erlacher L. Cartilage-derived morphogenetic protein-1 and -2 are endogenously expressed in healthy and osteoarthritic human articular chondrocytes and stimulate matrix synthesis. Osteoarthritis Cartilage 2002; 10:394-401.

33 Bobacz K, Gruber R, Soleiman A, Erlacher L, Smolen J, Graninger WB. Bone morphogenetic protein- 6 is expressed in healthy and osteoarthritic human articular chondrocytes and stimulates matrix synthesis in vitro. Arthritis Rheum 2003:48:2501-8

34 Brocklehurst R, Bayliss MT, Maroudas A, Coysh HL, Freeman MAR, Revell PA, et al. The composition of normal and osteoarthritic articular cartilage from human knee joints. With special reference to unicompartmental replacement and osteotomy of the knee. J Bone Joint Surg Am 1984:66:95-106.

35 Bayliss MT, Osborne D, Woodhouse S, Davidson CJ. Sulfation of chondroitin sulfate in human articular cartilage. The effect of age, topographical position, and zone of cartilage on tissue composition. Biol Chem 1999;274:15892-900. 
36 Quintero M, Mitrovic DR, Stankovic A, de Seze S, Miravet L, Ryckewaert A. Cellular aspects of the aging of the articular cartilage. II. Condylar cartilage with fissured surface taken from normal and arthritic knees. Rev Rheum 1984;51:445-9.

37 Doherty M, Hutton C, Bayliss M. Osteoarthritis. In: Maddison P, Isenberg D, Woo P, Glass D, eds. Oxford textbook of rheumatology. Oxford: Oxford University Press, 1993:959-83.

38 Aigner T, Bertling W, Stoss H, Weseloh G, von der Mark K. Independent expression of fibril-forming collagens I, II, and III in chondrocytes of human osteoarthritic cartilage. J Clin Invest 1993;91:829-37.
39 Nimni M, Deshmukh K. Differences in collagen metabolism between normal and osteoarthritic human articular cartilage. Science 1973;181:751-2.

40 Guerne P, Blanco F, Kaelin A, Desgeorges A, Lotz M. Growth factor responsiveness of human articular chondrocytes in aging and development. Arthritis Rheum 1995;38:960-8.

41 Blanco FJ, Guitian R, Vazquez-Martul E, de Toro FJ, Galdo F. Osteoarthritis chondrocytes die by apoptosis. A possible pathway for osteoarthritis pathology. Arthritis Rheum 1998;41:284-9.

42 Hashimoto S, Ochs RL, Komiya S, Lotz M. Linkage of chondrocyte apoptosis and cartilage degradation in human osteoarthritis. Arthritis Rheum 1998;41:1632-8

\section{Clinical Evidence-Call for contributors}

Clinical Evidence is a regularly updated evidence-based journal available worldwide both as a paper version and on the internet. Clinical Evidence needs to recruit a number of new contributors. Contributors are healthcare professionals or epidemiologists with experience in evidence-based medicine and the ability to write in a concise and structured way.

Areas for which we are currently seeking authors:

- Child health: nocturnal enuresis

- Eye disorders: bacterial conjunctivitis

- Male health: prostate cancer (metastatic)

- Women's health: pre-menstrual syndrome; pyelonephritis in non-pregnant women However, we are always looking for others, so do not let this list discourage you.

Being a contributor involves:

- Selecting from a validated, screened search (performed by in-house Information Specialists) epidemiologically sound studies for inclusion.

- Documenting your decisions about which studies to include on an inclusion and exclusion form, which we keep on file.

- Writing the text to a highly structured template (about 1500-3000 words), using evidence from the final studies chosen, within 8-10 weeks of receiving the literature search.

- Working with Clinical Evidence editors to ensure that the final text meets epidemiological and style standards.

- Updating the text every six months using any new, sound evidence that becomes available. The Clinical Evidence in-house team will conduct the searches for contributors; your task is simply to filter out high quality studies and incorporate them in the existing text.

- To expand the topic to include a new question about once every 12-18 months.

If you would like to become a contributor for Clinical Evidence or require more information about what this involves please send your contact details and a copy of your CV, clearly stating the clinical area you are interested in, to Klara Brunnhuber (kbrunnhuber@ bmigroup.com).

\section{Call for peer reviewers}

Clinical Evidence also needs to recruit a number of new peer reviewers specifically with an interest in the clinical areas stated above, and also others related to general practice. Peer reviewers are healthcare professionals or epidemiologists with experience in evidence-based medicine. As a peer reviewer you would be asked for your views on the clinical relevance, validity, and accessibility of specific topics within the journal, and their usefulness to the intended audience (international generalists and healthcare professionals, possibly with limited statistical knowledge). Topics are usually 1500-3000 words in length and we would ask you to review between 2-5 topics per year. The peer review process takes place throughout the year, and our turnaround time for each review is ideally 10-14 days.

If you are interested in becoming a peer reviewer for Clinical Evidence, please complete the peer review questionnaire at www. clinicalevidence.com or contact Klara Brunnhuber (kbrunnhuber@bmigroup.com). 